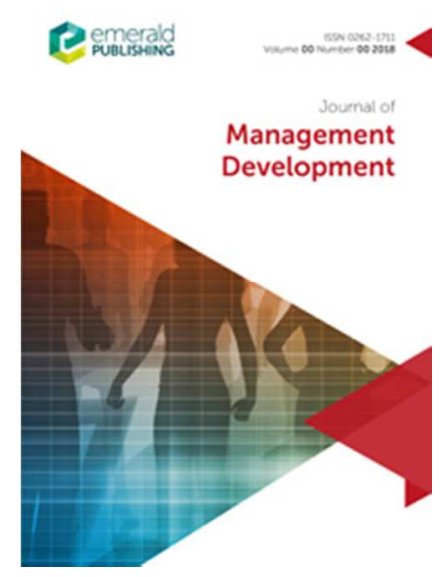

\title{
Reflective Vicarious Learning (RVL) as an enhancement for Action Learning
}

\begin{tabular}{|r|l|}
\hline Journal: & Journal of Management Development \\
\hline Manuscript ID & JMD-11-2017-0348.R1 \\
\hline Manuscript Type: & Original Article \\
\hline Keywords: & $\begin{array}{l}\text { Key words: Action learning, vicarious learning, goldfish bowl exercise, } \\
\text { Action Learning, Education, Executive training, General management, } \\
\text { Learning }\end{array}$ \\
\hline \multicolumn{2}{|l}{} \\
\hline
\end{tabular}

SCHOLARONE ${ }^{m}$

Manuscripts 


\title{
Vicarious Learning as an enhancement for Action Learning
}

\begin{abstract}
Purpose

A fundamental assumption within Action Learning is that learning only occurs through participation, reflection and action. Revans maintains that individuals will fail to understand the 'how' of an experience until they have experienced it for themselves i.e. 'learned by doing'. This paper postulates that Revans' concept of 'learning by doing' can in certain circumstances be enhanced through vicarious learning or learning from the behaviour of others.
\end{abstract}

Design, methodology and approach

This paper adopts a desk research approach review of literature, accompanied by the authors own experience of facilitating action learning sets and the goldfish bowl exercise.

Findings

The author maintains that Revans' concept of 'learning by doing' in the context of the goldfish bowl exercise can enhance insight an individual's insight through vicarious learning or learning from the behaviour of others.

Research implications and limitations

The paper is limited in some respects as it focuses on the viewpoint of the author coupled with literature. Future research could explore participant voices to add an extra dimension to the work.

Originality 
This paper originality is that seeks to enhance Revan's proposition by illustrating how vicarious learning can enhance learning in situations where participation is not possible.

Practical implications

In terms of utility for others, this paper is useful for developing an understanding of the differing learning opportunities that action learning offers. As such, it has meaning for action learning facilitators, set members, academics and educational consultants.

\section{Key words:}

Action learning, vicarious learning, goldfish bowl exercise

\section{Article Classification:}

Viewpoint

\section{Acknowledgement:}

I'd like to formally recognise the contribution that Dr Roger David Hall made to this paper. My friend and colleague Roger sadly passed away before the publication of this work, I promised myself that I would finish it. I dedicate this contribution to knowledge to his memory.

\section{Introduction}

The fundamental assumption within action learning is that 'there is no learning without action and no action without learning' Revans, (2011:85). The premise is that learning 
can only take place through participation, reflection and action (McGill and Beaty, 1992). Revans maintains that individuals will fail to understand the 'how' of an experience until they have experienced it for themselves i.e. 'learned by doing'. Aristotle's wisdom that " For the things we have to learn before we do them, we learn by doing them", written around 350 BCE, in the Nichomachean Ethics (Broadie, 1991: 104) is both obvious and common sense, but is largely ignored within conventional learning and education generally. Arguably, "learned or learning by doing" is a natural activity, part of growing up during which we learn through both a mixture of simulation and emulation and the subsequent reflections upon the process (Felicia, 2011).There is, however, a seeming disparity between Revans' concept of 'learning by doing', (in which he emphasised that the individual should actually engage in action themselves in order to learn from their own experiences), and one particular aspect of social learning theory - vicarious learning or learning from the behaviour of others. The concept derives from the work of Bandura (1977) and has been defined as: "a process that allows an observer of another individual's model behaviour to change his (sic) behaviour without directly experiencing the consequences." (Void and Drury, 2006:1054).

The paper commences with a brief literature review of the salient elements of the subject: action learning, vicarious learning and the goldfish bowl exercise. It then draws these themes together in the form of a discussion, concluding that vicarious learning can act as an enhancement to learning in situations when it is not possible to actually participate in the experience.

\section{Action learning}


Action learning has long been recognised as amongst the most effective means of delivering professional education and management development training (Zuber-Skerritt, 2002; Kramer, 2008). In its most usual form, it is a continuous process of learning and reflection that occurs with the support of a group or 'set' of approximately six to eight colleagues, working on real issues with the intention of getting things done.

There are three distinct roles that are played in an action learning set when it is in operation. Usually there is one person presenting, one facilitating and the others are enabling (sometimes called supporting). The role of the facilitator is to help the group learn through focusing on the action learning process. It must be said though, Revans was initially opposed to the use of a facilitator. He believed the action learning set would be able to practise action learning on its own, thereby not risking the set becoming dependent on a facilitator. The voluntary participants in set learn with and from one another and take forward an important issue with support of the other members of the set. The collaborative process, which recognises each set member's social context, promotes the premise that managers learn most effectively with, and from, other managers whilst dealing with the real world complexity of organisational life.

The effectiveness of action learning, it has been suggested, lies in its resonances with the major theories of adult learning. As Marquardt and Waddill (2004:199) argue:

The power and success of learning that occurs within the action learning process can be attributed to the fact that it incorporates so many different and disparate theories of learning

They examine the links with what they describe as five schools of adult learning cognitivism, behaviourism, humanism, social learning theory and constructivism - and conclude that action learning "serves as a bridge between the different adult learning schools 
rather than a wall.” (2004:199). The thrust of their argument is that action learning does not exclude other approaches to learning but rather encourages their inclusion within an actionAs with most educational processes, educationalists and practitioners have deviated from Revans' original view of the process by adapting some of its principles in order to accommodate their own educational or organisational needs, beliefs and experiences.

\section{Experiential learning}

Experiential learning is the cognitive process of an individual's learning through experience, and can be more specifically defined as "learning through reflection on doing" (Felicia, 2011:1003), which is often contrasted with rote or didactic learning. Experiential learning focuses on the individual actually carrying out a task and experiencing what is actually involved in doing the task, things that may not be apparent when the task is simply theorised about, as opposed to simply reading about how the task should be completed. The result is first-hand knowledge, as opposed to simply reading or hearing about others' experiences. However, though the gaining of knowledge is an inherent process that occurs naturally, for a genuine learning experience to occur, certain elements must exist Kolb (1984), drawing on the work of Lewin (1949), said that knowledge is continuously gained through both personal and environmental experiences, stating that in order to obtain knowledge from an experience, certain conditions must be met:

1. The learner must be willing to be actively involved in the experience;

2. The learner must be able to reflect on the experience;

3. The learner must possess and use analytical skills to conceptualise the experience;

4. The learner must possess decision making and problem solving skills in order to use the new ideas gained from the experience. 
Despite critiques of experiential learning theory, empirical and theoretical, summarised

by Kayes (2001), it still has a wide impact on management learning. Experiential

learning can be seen as engaging the learner at a more personal level by addressing the needs and wants of the individual and requires qualities such as self-initiative and self-evaluation. For experiential learning to be truly effective, it should employ the whole learning process, from goal setting, to experimenting and observing, to reviewing, and finally action planning. The process facilitates the development of new skills, attitudes or in some instances, entirely new ways of thinking. At this stage it is useful to consider Kolb's (1984) learning cycle that shows four distinct learning styles sometimes known as 'learning preferences', which are based on a four stage learning cycle. Kolb (1984) includes in this cycle learning as a central principle in his experiential learning theory, typically expressed as a four stage cycle of learning, in which 'immediate or concrete experiences' provide a basis for 'observations and reflections'. These 'observations and reflections' are assimilated and distilled into 'abstract concepts', producing new implications for action which can be actively tested in turn creating new experiences. Kolb (1984) said that ideally this process represents a learning cycle or spiral where the learner moves through all stages, i.e. a cycle of experiencing, reflecting, thinking and acting. These reflections are then assimilated (absorbed and translated) into abstract concepts with implications for action, which the individual can actively experiment with. Kolb's model therefore works in the following way:

1. Concrete Experience - (CE)

2. Reflective Observation- (RO)

3. Abstract conceptualisation - (AC)

4. Active Experimentation - (AE) 


\begin{abstract}
In the context of higher education, experiential learning in Business School programs has become more important. For example, Clark \& White (2010) point out that "a quality university business education program must include an experiential learning component". Knowledge, skills and experience are acquired outside of the traditional classroom or lecture room, and usually include internships, studies abroad, field trips, field research and placements.
\end{abstract}

Vicarious learning

Literature maintains that there are a variety of differing definitions of vicarious learning which include: being able to observe or 'listen in' on experts or peers as they discuss a new topic (Cox et al: 1999); learning through the experiences of another (Fox, 2003). Bruner (1986:122) states that "most of our encounters with the world, are not direct encounters", the implication being that learning may occur through means other than first-hand experience.

In a review of the literature on vicarious learning in nurse education, Roberts, (2010) shows how students can use at second-hand the experiences of their peers to learn for themselves. She concludes that students internalise what is said during discourse, discussion and storytelling and relate these ideas to their own context. In the context of action learning the idea of vicarious learning may, at first sight, seem anomalous. Yet our own experiences of developing action learning sets point to benefits of introducing opportunities for vicarious learning, particularly in the early stages.

\title{
Action learning and vicarious learning
}

Revans' concept of action learning shares many characteristics with andragogy (Knowles, 1973 ) or adult learning theory (Howell, 1994), including self-direction, experience and motivation. There are strong resonances between Revans' system beta [Survey, Hypothesis, 
Experiment, Audit, Review] and adult learning cycles made familiar by Lewin (1951), Kolb (1984), Honey and Mumford (1992) and Deming (1986).

In contrast, vicarious learning, which is part of social learning theory, focuses essentially on developmental learning, particularly in children. Bandura's famous experiments with a Bobo doll in the early 1960s were with children. Yet Bandura's (1977:22) statement that:

Learning would be exceedingly laborious, not to mention hazardous, if people had to rely solely on the effects of their own actions to inform them what to do.

Fortunately, most human behavior is learned observationally through modeling: from observing others one forms an idea of how new behaviors are performed, and on later occasions this coded information serves as a guide for action

is surely relevant in adult learning. If vicarious learning is used carefully in an action learning context, it may contribute to the effectiveness of learning. Bingham and Davis (2012) writing on learning sequences in organisations found evidence of sequences of learning in organisations, where vicarious learning precedes direct learning, a process they describe as seeding, this leads to a later expansion of direct learning and longer term performance benefits. Referring to the work of Baum et al. (2000), Henisz and Delios (2001), and Kraatz (1998), the authors argue that vicarious learning is useful in new situations and where uncertainty is high. Although this paper's focus is on organisational learning, the concept of seeding may usefully be applied to an action learning set where, for most participants it is a new experience with high uncertainty and where learning is taking place in a group setting.. The authors examine vicarious learning in an entrepreneurial setting. Citing the work of Wood and Bandura (1989), they argue that: 
Vicarious learning provides a basis for subsequent action in less familiar domains.

For instance, effective learning through vicarious means teaches people general rules and strategies for approaching new situation.

Once again this argument can be transferred to action learning sets where most first-time participants are unfamiliar with the concepts and behaviours involved. The action learning set may be considered as an unfamiliar domain and familiarity may quickly be gained vicariously through observing the actions of others and reflecting on how these actions can be translated into the observers' own situations.

Revans' (2011:3) equation that Learning = Programmed knowledge + Questioning insight has been long discussed in the action learning literature. As Mumford (2006) points out, Revans himself was fairly dismissive of the value of programmed learning. Participants in early action learning programmes were critical of the amount of programmed knowledge given to them at the beginning of their programme (Mumford, 2006:71).

How then do we begin to reconcile the views of Revans and other practitioners with research findings about vicarious learning? Is it the case that vicarious learning is valuable in all situations except action learning? Does any type of vicarious learning weaken the impact of action learning or are there ways of introducing participants to action learning which augment the learning through action? Use of the classroom goldfish bowl is one example.

\section{The 'goldfish bowl' exercise}

In seeking to explain how action learning works, it is useful to consider an exercise called the 'goldfish bowl', which is commonly used in training scenarios. In this exercise, people see the learning process in action as opposed to reading about it. Here the metaphor instantly 
conjures up imagery of looking from the outside into the goldfish bowl whilst observing the activity inside. Place this metaphor in the context of an action learning set. Spectators are offered an insight into the processual elements within an action learning set and it is possible to see the differing facets involved e.g. various approaches to listening and hearing, types of questions used e.g. questioning insight (Revans, 1983) and insightful questions (Brockbank and McGill 1998) and a range of facilitation skills used to manage the learning process. In the goldfish bowl exercise the facilitator positions the seats so that people sitting on chairs in an 'outer' ring, observe the people in the action learning set sitting together as an 'inner' group. Members of the action learning set sit facing each other with their backs to the outer ring of people. An empty chair is placed in the circle to facilitate a member from the outer group stepping in to ask a question if desired, then leaving the seat to facilitate another person stepping in. The facilitator then describes the types of questions to be used, stressing the importance of the style of questioning, which should be supportive and at no point should the enablers start to give the presenter their opinion on how to resolve the issue.

The facilitator initiates the start of the set where members start listening to one of the member's issue, at this point is should be said that the presenters issue is not a fabricated one, it has real meaning to them, and in order to secure someone in this role, the experience is presented as being an opportunity to get feedback from a group of individuals who are neutral. At the end of the set time for this exercise, which may only be fifteen minutes, the members of the action learning set feedback their observations and feelings first as to how the set went, followed by the outer group feeding back their observations on the proceedings.

This exercise aims to create an awareness of differing perspectives on a given issue. Observers outside the goldfish bowl are encouraged to reflect on what they see; to consider the differing forms of communication occurring; listening, hearing, body language and demeanour displayed by the actual members of the action learning set . The description of 
the 'gold-fish bowl exercise' clearly highlights how the action learning process can be extended to include a wider group of participants who then have the opportunity to learn through the experiences of others. By offering the audience an opportunity to develop a better understanding of how action learning works, it arguably removes the abstract element of the process. There is an apparent paradox between Revans' (2011:85) statement that "there is no learning without action" and Bandura's (1977:22) statement that "most human behaviour is learned observationally through modelling". On the face of it, both statements seem to be true, but they are mutually incompatible, so cannot both be true. In order to resolve the apparent paradox, we start with different understandings of what learning is. Revans never defined learning but it would be fair to assume that he took a behavioural view, that, notwithstanding knowledge, understanding, beliefs, attitudes and feelings, true learning does not occur until we have acted. Vicarious experience provides us with a repertoire or palette of behaviours from which we may choose our own. The choice is necessarily restricted to a narrow segment of the spectrum through limitations of others' experience and by what we consider appropriate to ourselves. Thus vicarious learning is essentially in the cognitive and affective domains. Although it may provide guidance for our own actions through modelling, it is only when we enact that guidance through our own behaviours that deep learning occurs. At various times in our lives we may meet people or encounter situations where a different part of the palette of behaviours is demonstrated. If we show positive affect towards these new behaviours we may act to amend our own approaches to situations and thereby learn new behaviours.

In order to further understand and resolve the seeming paradox between learning by doing and learning from others, it is helpful to distinguish between two processes - learning how to operate within an action learning set and applying the precepts of action learning in the workplace. The former may be thought of as a meta-skill, - learning how to learn - a form of 
triple-loop learning (Tosey et al., 2012). The fishbowl provided an example of how an action learning set might operate in practice. This emphasised the value of gaining an understanding of action learning through reading and gaining a deeper feel for the process from observation of others. In particular, the opportunity to reflect upon others learning and what that may mean for their own individual learning. It would still be necessary for individuals to experiment with both presenting and enabling and with changing their behaviours and approaches in the workplace. There is no paradox. Vicarious learning can act as a support for action learning by making people better able to utilise the process quickly and effectively. The question remains as to how precisely this can happen within an action learning set.

\section{Discussion}

It is well understood that declaratory knowledge, which is largely in the cognitive domain, builds on what has gone before (on the shoulders of giants) but, what about learning in other domains, for example: affective and behavioural? Anecdotally, we are certainly less willing here to use the experience of others to influence others. How many teenagers take any notice of their parents, for example? How often are societies destined to repeat the mistakes of their predecessors? Why are members of action learning sets able to learn to modify their emotions and behaviours?

Recent literature in the field of management education has focused on group learning, student-centred learning and reflective skills development in the classroom. Learning has been shown to improve through a focus on student-centred cases in the classroom (Foster and Carboni, 2009) and through a student-driven service--learning and problem-based learning system (Robinson et al., 2010). Bedrow and Evers (2011) have shown how learner-centred self-reflection can enhance base competencies of graduates. This is reinforced by Hibbert (2013) and by Inamdar and Roldan (2013) who argue for the integration of theoretical, 
practical, applied and reflective skills. Welsh and Dehler (2013) have combined critical reflection and design thinking to develop students as integrative learners whilst Berggren and Soderlund (2011) have demonstrated how an approach grounded in experiential action learning can combine personal learning and organisational action without compromising academic standards. Borredon et al. (2011) identify some issues with implementing learning teams in French classrooms, which implies that such initiatives may be culture-dependent. In America the effectiveness of group work on MBA programmes is well-established. (Rafferty, 2013)

Group learning, participant focus and reflective practice are all necessary features of action learning sets but they do not fully explain how emotions and behaviours can be changed.If we begin with the particular context of the action learning set we can see that the action learning set has a psychological climate that is very different from most social settings, particularly where the politics of same-organization membership are not present. Psychological climate, as distinct from organisational climate, refers to the dominant psychological atmosphere or ambience in a particular group (Koys and Decotis, 1991; Jones and James, 1979).It is something that is felt by individual members and acts as the basis for the way that they behave in the group (Schneider, 1983) Rousseau (1988:140) defined it as "essentially, climate is individual descriptions of the social setting or context which a person is a part”. If participants in action learning sets are truly comrades in adversity (Revans,1982) as opposed to adversaries in commonality (Vince,2004) then this perhaps allows for the development of trust and authentic behaviour, such that personal accounts are more compelling at an emotional level. In many cases the courses of action that people have taken have been agreed by the set. In such cases there is an emotional investment in the outcome a belief that this is part of me and that we may truly be able to learn from others' actions and 
behaviours without trying these out for ourselves, with specific reference to the goldfish bowl exercise. There will, it is true, be a lessening of visceral feeling, but some of that will be present and it is that which allows affective learning. To some extent we can intellectualise behaviour and be instrumental in adapting this to influence events as the courtesan and the con-man do all the time. It is more difficult to intellectualise our emotions to any great extent. Do we need to experience fear, disappointment, anger, joy and disgust to know what they are like and how they impact on our behaviour. Occasionally in our normal lives we might develop sufficient empathy to learn emotionally through others. Perhaps an action learning set can create the conditions in which second-hand learning becomes a focus. We encourage others to try out new behaviours and change their emotional stance through reframing; they in turn feed back to us about what they did and how they felt so that we are a small part of them.

Revans famously did not define action learning. It is reasonable to assume that learning for Revans involved behavioural shifts rather than knowledge and understanding. The very fact that action learning takes place within sets or groups of people implies that people do learn from one another. Vicarious learning is an essential part of being in an action learning set and, as learning is not substantially in the cognitive domain, the experiences of others clearly impact on an individual's behaviour and the associated emotions. Recent developments in neuroscience and practices of neuro-linguistic programming and cognitive behavioural therapy point to a convergence between knowing and doing, which has significant implications for enabling behavioural change. Action learning sets are a powerful vehicle for such change.

\section{Conclusion}


As stated in the introduction, there is no wish to contradict Revans' views, but simply to add to his work by exploring how vicarious learning experiences can enrich the work in this field.

The paper simply seeks to provide a valuable insight into how vicarious learning can be beneficial in situations when it is not possible to actually participate in the experience itself.

\section{References}


Bandura, A. (1977), Social Learning Theory, Englewood Cliffs, NJ, Prentice-Hall. Bandura,

Baum, J. A. C., Li, S. X. \& Usher, J. M. (2000), “Making the next move: how experiential and vicarious learning shape the locations of chains' acquisitions", Administrative Science Quarterly, 45, $766-701$.

Bedrow, I. \& Evers, F. T. (2011), "Bases of competence: a framework for facilitating reflective learner-centered educational environments", Journal of Management Education, $35,406-427$.

Berggren, C. \& Soderlund, J. (2011), “Management education for practicing managers: combining academic rigor with personal change and organizational action”, Journal of Management Education, 35(3), 377 - 405.

Bingham, C. B. \& Davis, J. P. (2012), "Learning sequences: their existence, effect and evolution”, Academy of Management Journal, 55(3), 611 - 641.

Borredon, L., Deffayet, S., Baker, A. C. \& Kolb, D. (2011), “Enhancing deep learning: lessons from the introduction of learning teams in management education in France", Journal of Management Education, 35(3) 324 - 350.

Brockbank, A \& McGill, I. (1998). Facilitating Reflective Learning in Higher Education, Open University Press.

Broadie, S (1991). Ethics with Aristotle, Oxford University Press, Oxford.

Bruner, J.S., (1969), On Knowing. Essays for the Left Hand. Atheneum. Reprinted by arrangement with Harvard University Press, Massachusetts, USA.

Clark, J., \& White, G. (2010)' "Experiential Learning: A Definitive Edge In The Job Market". American Journal of Business Education, 3(2), 115-118. 
R. Cox, J. McKendree, R. Tobin, J. Lee \& T. Mayes. (1999), Vicarious learning from dialogue and discourse. Instructional Science, 27,431-458.

Deming, W. E. (1986), Out of the crisis: quality, productivity and competitive position. Cambridge, Cambridge University Press.

Foster, P. \& Carboni, I. (2009), “Using student-centered cases in the classroom”, Journal of Management Education, 3,6, 676 - 698.

Felicia, P (2011), Handbook of Research on Improving Learning and Motivation. ISBN 1609604962.

Fox F.F. (2003), Reducing intercultural friction through fiction: virtual cultural learning, International Journal of Intercultural Relations, 27, 99-123.

Henisz, W. J. \& Delios, A. (2001), “Uncertainty, imitation and plant location: Japanese multinational corporations, 1990 - 1996”, Administrative Science Quarterly, 46, 443 - 475.

Hibbert, P. (2013), “Approaching reflectivity through reflection: issues for critical management education", Journal of Management Journal of Management Education, December, 33(6), $676-698$.

Holcomb, T. R., Ireland, R. D., Holmes Jr., R. M. \& Hitt, M. A. (2009), “Architecture of entrepreneurial learning: exploring the link among heuristics, knowledge and action", Entrepreneurship, Theory and Practice, $167-192$.

Honey, P \& Mumford, A. (1982), The Manual of Learning Styles, Maidenhead: Peter Howell, F. (1994), “Action learning and action research in management education: a case study", The Learning Organization, 1,(6), 15 - 22. 
Inamdar, S. N. \& Roldan, M. (2013), “The MBA capstone course: building theoretical, practical, applied and reflective skills", Journal of Management Education, December, 37(6), $747-770$.

Jones, A.P \& James, L.R. (1979), Psychological climate; dimensions and relationships of individual and aggregated work environment perceptions, Organisational Behaviour and Human Performance, 23 (2), 201-250.

Kayes, C (2001), The fractured figure eight: exploring the relationship between social and personal knowledge, Paper presented at: Conference for organisational learning and knowledge management, London, OT, Canada.

Kraatz, M. S. (1998), "Learning by association? Interorganizational networks and adaptation to environmental change", Academy of Management Journal, 41,621 - 643.

Knowles, M. S. (1973), The Adult Learner: a neglected species. Houston, Gulf Publishing. Kolb, D. (1984), Experiential Learning, Prentice-Hall, Englewood Cliffs, NJ.

Koys, D.J \& DeCotis, T.A (1991), Inductive measures of psychological climate. Human Relations, 44 (3), 265-285.

Kramer, R. (2008), Learning How to Learn: Action Learning for Leadership Development. In Morse (Ed.) Innovations in Public Leadership Development. Washington DC: M.E. Sharpe and National Academy of Public Administration, 296-326.

Lewin, K. (1949), Field Theory in Social Sciences. New York. Harper and Row. Lewin, K (1949), Experience and Education, Kappa Delta Pi, New York, NY 
Lewin, K. (1951), Field theory in social science: selected theoretical papers, (Ed. Dorwin Cartwright). Oxford, Harpers.

Marquardt, M. \&, Waddill, D. (2004), “The power of learning in action learning: a conceptual analysis of how the five schools of adult learning theories are incorporated within the practice of action learning." Action Learning: Research and Practice, 1(2), 185-202.

McGill, I. \& Beatty, L. (1992). Action learning: A practitioner's guide, London, Kogan Page.

Mumford, A. (2006), “Action learning: nothing so practical as a good theory”, Action Learning: Research and Practice, 3(1) 69-75.

Rafferty, P. D. (2013),“Group work in the MBA classroom: improving pedagogical practice and maximising positive outcomes with part-time MBA students", Journal of Management Education, October, 37 (5) 623 - 650.

Revans, R (2011), ABC of Action Learning, Gower, Farnham.

Revans, R, W. (1982), The origin and growth of Action Learning, London: Chartwell Bratt.

Revans, R. W. (1983), The ABC of Action Learning, Chartwell-Bratt Student literature.

Roberts, D. ((2010), "Vicarious learning: A review of the literature." Nurse Education in Practice 10, 13-16.

Robinson, D. F., Sherwood, A. L. \& DePaolo, C. A. (2010),“Service-learning by doing”, Journal of Management Education, 34 (1) 88 - 112.

Rousseau, D.M. (1988), The construction of climate in organizational research. International Review of Industrial and Organizational Psychology, 3 139-158. New York: Wiley. 
Scheider, B. (1983), Work climates: an interactionist perspective. In N.W Feimer and Es

Geller (eds) Environmental Psychology: Directions and Perspectives, New York: Praeger

Tosey, P., Visser M. \& Saunders, M. N. K. (2012), “The origins and conceptualizations of ‘triple loop' learning”, Management Learning, 43 (3), 291 - 307.

Vince, R. (2004), Action learning and organizational learning: power, politics and emotion in organisations. Action Learning: Research and Practice. 1(1), 63-78.

Voit, J.R. \& Drury, C.G. (2006), “Supporting vicarious learning with collaborative lessons learned programs", IEEE: Transactions on Systems, Man, and Cybernetics - Part A:

Systems and Humans, 36(6), 1054-1062.

Welsh, M. A. \& Dehler, D. E. (2013), “Combining critical reflection and design thinking to develop integrative learners", Journal of Management Education, 37(6), 771 - 802.

Wood, R. \& Bandura, A. (1989), "Social cognitive theory of organizational management", Academy of Management Review, 14(3), 361 - 384.

(Zuber-Skerritt, (2002), An executive action learning program (SEAL) for professional development and higher degrees. In Management von Universitäten: Zwischen Tradition und Post-Moderne, ed. H. Welte, M. Auer \& C. Meister-Scheytt. Munich: Rainer Hampp Verlag. 


\section{Reviewer(s)' Comments to Author:}

Reviewer: 1

\section{Recommendation: Minor Revision}

Comments:

I enjoyed the conceptual nature of this paper.

The notion of RVL in the 2nd reflective phase of the action learning cycle is the core of this paper and must be highlighted. This is the contribution of this paper and what separates it from VL of others behaviours in Bandura's Social Learning Theory. I have reinforced that throughout Additional Questions:

$\langle b\rangle$. Originality: $\langle/ b\rangle$ Does the paper contain new and significant information adequate to justify publication?:

The paper does not contain new information but it does pose a very interesting question regarding the impact of vicarious learning in the action learning cycle - do, reflect, learn; specifically in the reflection phase.

Thank you, I thought so, but I feel I better articulate that now $\langle b\rangle 2$. Relationship to Literature: $\langle/ b\rangle$ Does the paper demonstrate an adequate understanding of the relevant literature in the field and cite an appropriate range of literature sources? Is any signficant work ignored?:

Yes it is adequate.

I think more definitions of learning must be included and experiential learning and action learning placed within the over learning definition. Example: learning is a of change of behaviour, knowledge, values, attitudes, based on experience (action, vicarious, rote memorization, or other)

This has been addressed in a comprehensive review of learning theory, which aims to link all aspects of the appropriate theories that come under the umbrella of learning

$\langle b>3$. Methodology: $\langle/ b>$ Is the paper's argument built on an appropriate base of theory, concepts, or other ideas? Has the research or equivalent intellectual work on which the paper is based been well designed? Are the methods employed appropriate?:

The base of theory is adequate.

It is an appropriate conceptual argument, but I think it can be strengthened.

1. More of Bandura's work on vicarious learning must be included.His later papers clarify his earlier definitions of vicarious learning and provide greater detail. More of his publications must be included to convince the reader that the author has a thorough understanding of both 
Bandura's works.

This has now been addressed in the paper

$\langle\mathrm{b}>4$. Results: $\langle/ \mathrm{b}>$ Are results presented clearly and analysed appropriately? Do the conclusions adequately tie together the other elements of the paper?:

1.The notion of Bandura's vicarious learning through observation of others behaviours takes place in the 1st phase of the action learning cycle, i.e. doing.

2. I think the author of this paper is focusing on vicarious learning in the 2nd phase of the action learning cycle, i.e reflecting. This is where I think the paper contributes to the field of action learning. Also if this is delineated and highlighted it will strengthen the paper by making it explicit exactly where the vicarious learning is taking place. this will help with the link to the conclusions.

3.I would encourage the author to create a new term - reflective vicarious learning, because this is what I see is the core contribution of this paper is to the action learning literature. This as opposed to vicarious learning though behaviour modeling. Many facilitators may have been doing reflective vicarious learning when they debriefed their experiential learning activities

4. What is not clear and which needs explicit detail is "who has learned through reflective vicarious learning" in the fish bowel activity. Was it the inside group, or the outside group, or both groups? the author has mentioned that this is an area that could be researched.

As you can see, right from the very start I have claimed the title Reflective Vicarious l Learning (RVL) and this now permeates the paper. And the question "who has learned through reflective vicarious learning" in the discussion on page 16.

$<b>5$. Implications for research, practice and/or society: $</ b>$ Does the paper identify clearly any implications for research, practice and/or society? Does the paper bridge the gap between theory and practice? How can the research be used in practice (economic and commercial impact), in teaching, to influence public policy, in research (contributing to the body of knowledge)? What is the impact upon society (influencing public attitudes, affecting quality of life)? Are these implications consistent with the findings and conclusions of the paper?

: I.I think the best implications for research on reflective vicarious learning (RVL) will be in the reflective phase of experiential/action learning. As noted in \#4 above, does RVL impact the learning of participants or the observers, or both. This opens up a new line of research. See point above above

2. I think this paper expands the notion of RVL in many practical areas. Example \#1: In student group presentations the audience of students often gives feedback to the individual or the team presenting. RVL is used for the presenters but it can also be used by the audience of students to RVL for their next presentation. 3. RVL can be expanded to many similar situations in which there are observers. Agreed, and hopefully the reader 
will appreciate that it can extend beyond action learning

$\langle b\rangle$. Quality of Communication: $\langle/ b\rangle$ Does the paper clearly express its case, measured against the technical language of the field and the expected knowledge of the journal's readership? Has attention been paid to the clarity of expression and readability, such as sentence structure, jargon use, acronyms, etc.:

I think the technical language is good. Thank you

\section{Reviewer: 2}

Recommendation: Minor Revision

Comments:

A relevant paper, useful to both researchers and practitioner in the field of Management Development.

It is suggested that you consider revisiting, referring and including aspects of Experiential Learning in the discussion and conclusion. otherwise, it seems to me, that you have dedicated a whole section to it, just for the sake of mentioning it - looks like a stand alone section with hardly any reference to it as the paper develops.

I also suggest that you consider including aspects of Action Science (Argyris and Schon) as well as, perhaps the Learning Organisation (Senge) for a more complete account of major contributions to the development of organisational learning.

I totally agree on this point, the narrative on experiential learning has been integrated in a better way.

Additional Questions:

$\langle b>1$. Originality: $\langle/ b\rangle$ Does the paper contain new and significant information adequate to justify publication?:

Yes, the paper builds on previous knowledge and proposes fresh insights into the further development of Action Learning practice that is relevant to the area of management development. Thank you

$\langle b\rangle 2$. Relationship to Literature: $\langle/ b\rangle$ Does the paper demonstrate an adequate understanding of the relevant literature in the field and cite an appropriate range of literature sources? Is any signficant work ignored? :

The paper demonstrates a good understanding of the relevant literature. I suggest that Argyris and Schon's work on action science and single- and double-loop learning be included. This has not been incorporated

$<b>3$. Methodology: $\langle/ b>$ Is the paper's argument built on an appropriate base of theory, concepts, or other ideas? Has the research or equivalent intellectual work on which the paper is based been well designed? Are the methods employed appropriate? : 
Given that the paper is classified as a 'viewpoint' I think that the design is appropriate, however, I would have appreciated some factual 'critical' cases to substantiate the debate especially in terms of how

'vicarious' learning relates and complements the practice of Action Learning for Management Development. This is a useful comment, I have expanded on this is a conceptual way and now see this very point as a basis for future work.

$<$ b $>4$. Results: $</ b>$ Are results presented clearly and analysed appropriately? Do the conclusions adequately tie together the other elements of the paper?:

The article dedicates a whole section to Experiential Learning, and stops there! How does Experiential Learning contribute to the debate? For me it is not clear enough. I was expecting the paper to revisit in order to come up with a more comprehensive conclusion. This has now been integrated in a more balanced way

$<b>5$. Implications for research, practice and/or society: </b $>$ Does the paper identify clearly any implications for research, practice and/or society? Does the paper bridge the gap between theory and practice? How can the research be used in practice (economic and commercial impact), in teaching, to influence public policy, in research (contributing to the body of knowledge)? What is the impact upon society (influencing public attitudes, affecting quality of life)? Are these implications consistent with the findings and conclusions of the paper?:

Yes, there a strong and relevant implications for research and practice, albeit, not always clear, especially to the reader or practitioner who is new to Action Learning. Hopefully through my amendments and added explanation you will see that clarity

$\langle b\rangle 6$. Quality of Communication: $\langle/ b\rangle$ Does the paper clearly express its case, measured against the technical language of the field and the expected knowledge of the journal's readership? Has attention been paid to the clarity of expression and readability, such as sentence structure, jargon use, acronyms, etc.:

The is room for improvement, especially in terms of punctuation and referencing. The paper needs some polishing, e.g:

page 1, line 40 - delete 'insight'

page 2, line 2-5 - sentence need's rephrasing (+ Revans' not Revan's)

page 4, line 31 'the' set

page 5, line 12 - sentence incomplete

page 5, line 42 -full-stop after exist?

page 8, lines 23 to 36 - need revisiting, there seems to be something missing.

page 9, line 2 - not clear to me who 'the authors' are! page 9, lines 9 to 14 - if citation, page number is needed. 
1

2

3

4

5

6

7

8

10

11

12

13

14

15

16

17

18

19

20

21

22

23

24

25

26

27

28

29

30

31

32

33

34

35

36

37

38

39

40

41

42

43

44

45

46

47

48

49

50

51

52

53

54

55

56

57

58

59

60

page 10, line 44 'it' instead of 'is'. Not clear who the 'presenters' are - are they members of the set or outsiders?

page 13, lines 48 to 50 - the seems to be something missing in the quote.

Thank you for this detailed feedback which I have responded to. 